\title{
Trampoline-related injuries in children: a nationwide cross-sectional study in South Korea
}

\author{
Geonmoo Lee', Do Kyun Kim', Joong Wan Park', Young Ho Kwak, \\ Jae Yun Jung'
}

'Department of Emergency Medicine, Seoul National University Hospital, Seoul, Korea

${ }^{2}$ Department of Emergency Medicine, Seoul National University College of Medicine, Seoul, Korea

Objective Trampoline-related injuries have increased in South Korea. However, little research has been conducted on this topic. This study aimed to show the characteristics of pediatric trampoline-related injuries in South Korea and to investigate the factors associated with admission.

Methods A retrospective, cross-sectional study was conducted using data from South Korea's Emergency Department-based Injury In-depth Surveillance registry for dates between January 2011 and December 2016. All patients under 18 years of age with trampoline-related injuries were included. We divided the patients into two groups based on whether they were admitted or discharged. Odds ratios with 95\% confidence intervals were calculated to evaluate the factors associated with hospital admission for pediatric trampoline-related injuries.

Results $A$ total of 2,745 patients were enrolled and the incidence increased over time ( $P$ for trend $<0.01)$. The most common injury site was the lower extremity $(45 \%)$. Fracture was the most frequent diagnosis (34.3\%). Compared to the discharge group, the adjusted odds ratios (95\% confidence intervals) for hospital admission were 3.53 (1.73-7.17) for the teenage group, 2.62 (1.82-3.77) for upper extremity injuries, 18.48 (7.95-42.95) for fractures, 2.28 (1.35-3.86) for falls, and 2.04 (1.15-3.60) for collisions.

Conclusion Trampoline-related injuries in children have increased over time in South Korea. Most occur in children under the age of 12 years, but children between the ages of 13 and 18 years are at a higher risk for hospitalization. Also, injuries of the upper extremity, fracture, falling, and collision are risk factors for admission. Preventive strategies are needed to reduce trampoline-related injuries in children.

Keywords Trampoline; Injuries; Republic of Korea; Child

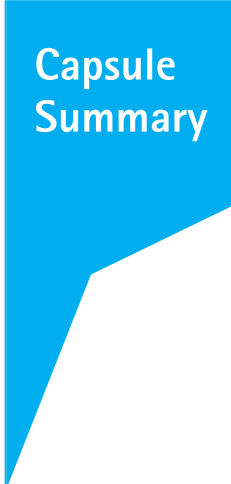

\section{What is new in the current study}

Most trampoline-related injuries in Korea occur in children under the age of 12 years, but children between the ages of 13 and 18 years are at a greater risk for hospitalization. Injury to an upper extremity and injury mechanism of fall or collision increase the likelihood of hospitalization.
eISSN: 2383-4625

Received: 9 July 2019

Revised: 26 September 2019

Accepted: 18 October 2019

Correspondence to: Do Kyun Kim Department of Emergency Medicine, Seoul National University Hospital, 101 Daehak-ro, Jongno-gu, Seoul 03080, Korea

E-mail: birdbeak@snuh.org ORCID

https://orcid.org/0000-0002-6144-302X

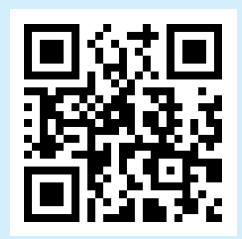

How to cite this article:

Lee G, Kim DK, Park JW, Kwak YH, Jung JY. Trampoline-related injuries in children: a nationwide cross-sectional study in South Korea. Clin Exp Emerg Med 2020;7(3):190196. https://doi.org/10.15441/ceem.19.060
This is an Open Access article distributed under the terms of the Creative Commons Attribution Non-Commercial License (https:// creativecommons.org/licenses/by-nc/4.0/). 


\section{INTRODUCTION}

Trampolines are devices with a flexible mat made for jumping or performing aerial movements. They are popular as playground equipment, attracting a great deal of attention from children. ${ }^{1}$ As trampolines gain popularity, trampoline-related injuries are increasing, and research in this regard has been conducted in the US and Europe. ${ }^{2,3}$ In one study in the United States, more than one million people visited hospital emergency departments (EDs) due to trampoline-related injuries over a 7-year period, and 288,876 (29.0\%) of these injuries were identified as fractures. ${ }^{4}$ A study from Finland showed that the annual incidence of severe trampoline injuries, such as cervical spine injury, in the pediatric population was 6.28 per $100,000 .{ }^{5}$ Based on these findings, recommendations and regulatory policies to prevent trampoline-related injuries are being made continuously.-7

As in many other countries, Korea has seen an increase in the number of trampolines and consequently in related injuries. According to a survey conducted by the Korea Consumer Agency in 2013, there are more than 400 facilities with trampolines, and trampoline-related injuries have been increasing steadily since $2010 .{ }^{8}$ Recently, several studies about trampoline-related injury have been reported in Korea. ${ }^{9-11}$ However, these studies showed only the epidemiological characteristics of the patients, and there have been no studies addressing the risk factors for severe trampoline-related injury.

The purpose of this study was to investigate the characteristics of trampoline-related injuries in Korean children and to identify the factors affecting hospital admission.

\section{METHODS}

\section{Study design, setting, and data source}

This study was a retrospective, cross-sectional study using data from the Korean national Emergency Department-based Injury In-depth Surveillance (EDIIS) registry from between January 2011 and December 2016. The EDIIS is a nationwide prospective clinical database of injured patients who visit the ED, which is supported by the Korea Centers for Disease Control and Prevention. EDs from 15 hospitals participated in the EDIIS in 2011, 17 hospitals participated in 2012 to 2014, 20 participated in 2015, and 23 participated in 2016. ${ }^{12}$

\section{Study population}

All patients under 18 years of age who were registered in the EDIIS database as having a trampoline-related injury between January 2011 and December 2016 were included. Cases of tram- poline-related injury were defined by the "primary or direct object of injury" EDIIS code category C10.03.10, which means trampoline. If "trampoline" and words that are similar to "trampoline" in Korean were included in the narrative data, we also defined those cases as trampoline-related injuries. We excluded cases that were not related to trampoline injury after a review of the narrative data.

\section{Variables and measurements}

We abstracted data including the patient's age, sex, injured anatomical site, the place where the injury occurred (indoor or outdoor), disposition after ED care (discharged, transferred, or admitted), discharge diagnosis, mechanism of injury, and whether the patient underwent surgery.

Injured anatomical sites were grouped for analysis into the following categories: head and neck, trunk, upper extremity, and lower extremity. Discharge diagnoses were grouped into the following categories: cerebral concussion, dislocation, fracture, open wound, sprain, superficial injury, and others. The mechanisms of injury were grouped into the following categories: collisions, overuse, falls, contact with another person, slips, and others.

\section{Statistical analysis}

To describe the characteristics of pediatric trampoline-related injuries in Korea, we divided the patients into four groups by age (0-3 years, 4-6 years, 7-12 years, and 13-18 years). Continuous variables were presented as medians and interquartile ranges. Categorical variables were presented as frequencies and proportions.

We divided the patients into two groups according to whether they were admitted, including those who were transferred to other hospitals or departments, or discharged. Then, odds ratios (OR) with $95 \%$ confidence intervals were calculated using a multivariable logistic regression analysis, in order to evaluate the factors associated with hospital admission in pediatric trampoline-related injuries.

All statistical analyses were performed using Stata ver. 14.2 (StataCorp., College Station, TX, USA). The level of statistical significance was defined as a P-value $<0.05$.

\section{Ethics statement}

This study was approved by the institutional review board of Seoul National University Hospital (1807-079-958). The institutional review board waived the need for informed consent LS:S, and patient information was anonymized prior to analysis. 


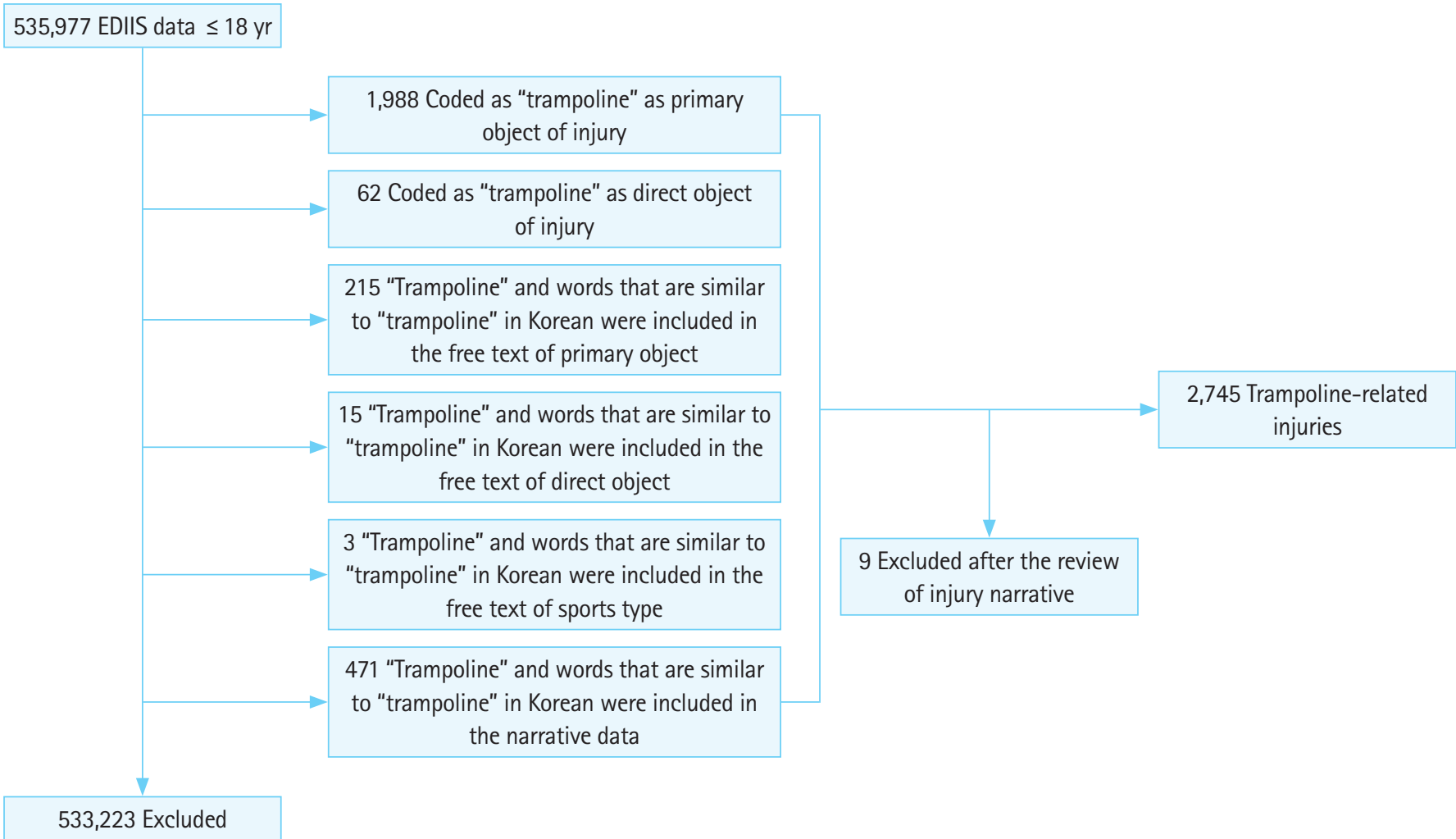

Fig. 1. Flowchart of study population selection process. EDIIS, Emergency Department-based Injury In-depth Surveillance.

\section{RESULTS}

Of the 1,537,617 injured patients during the study period, 1,001,640 patients older than 18 were excluded. We screened 535,977 patient entries (Fig. 1), from which we obtained 2,745 patients that we included in our study.

The annual rate of trampoline-related injuries per 1,000 injured pediatric patients increased throughout the study period ( $P$ for trend <0.001) (Fig. 2). Table 1 shows the baseline characteristics of pediatric trampoline-related injuries in Korea. The median age of the injured patients was 5 years (interquartile range, 3-8 years). The most common injured site was a lower extremity (45.0\%), followed by the head and neck (26.0\%), and an upper extremity $(24.4 \%)$. Fracture was the most frequent diagnosis (34.3\%), followed by superficial injuries (23.5\%) and sprains (19.7\%). The ED admission rate was $9.1 \%$, and $0.5 \%$ of patients were transferred out. In addition, three patients were admitted to the intensive care unit. Table 2 shows the demographic findings by ED disposition. Hospitalization was the most frequent in cases of upper extremity injuries, outdoor trampoline injuries, and fractures.

The results of the multivariable logistic regression models are presented in Table 3. Compared to the discharge group, the adjusted odds ratios were highest for the teenage group, for upper

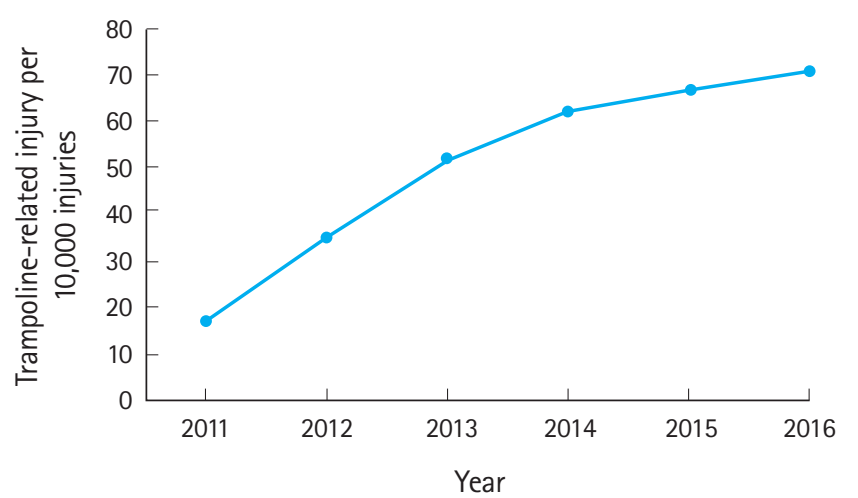

Fig. 2. Rate of pediatric trampoline-related injuries by year (per 10,000 injuries).

extremity injury, for fracture amongst wound characteristics, and for falls and collisions amongst identified injury mechanisms.

\section{DISCUSSION}

This study was conducted to investigate the characteristics and trends of pediatric trampoline-related injury in Korea and to identify the risk factors associated with admission to hospital. Although the prevalence of trampoline-related injury in children 
Table 1. Baseline characteristics of pediatric trampoline-related injuries by age group

\begin{tabular}{|c|c|c|c|c|c|}
\hline Characteristics & $\begin{array}{c}\text { Total } \\
(n=2,745)\end{array}$ & $\begin{array}{l}\text { Toddler }(0-3 \mathrm{yr}) \\
\quad(n=801)\end{array}$ & $\begin{array}{l}\text { Preschooler }(4-6 \text { yr }) \\
(n=912)\end{array}$ & $\begin{array}{c}\text { Schooler }(7-12 \text { yr }) \\
\quad(n=955)\end{array}$ & $\begin{array}{c}\text { Teenager }(13-18 \mathrm{yr}) \\
(\mathrm{n}=77)\end{array}$ \\
\hline Age (yr) & $5(3-8)$ & & & & \\
\hline \multicolumn{6}{|l|}{ Anatomical site } \\
\hline Head and neck & 714 (26.0) & $224(28.0)$ & $213(23.4)$ & $246(25.8)$ & $31(40.3)$ \\
\hline Trunk & $76(2.8)$ & $12(1.5)$ & $23(2.5)$ & $38(4.0)$ & $3(3.9)$ \\
\hline Unspecified & $58(2.1)$ & $15(1.9)$ & $21(2.3)$ & $19(2.0)$ & $3(3.9)$ \\
\hline \multicolumn{6}{|l|}{ Injury place } \\
\hline Indoor & $1,908(69.5)$ & $623(77.8)$ & $629(69.0)$ & $610(63.9)$ & $46(59.7)$ \\
\hline Outdoor & $761(27.7)$ & $159(19.9)$ & $252(27.6)$ & $324(33.9)$ & $26(33.8)$ \\
\hline Unspecified & $76(2.8)$ & $19(2.4)$ & $31(3.4)$ & $21(2.2)$ & $5(6.5)$ \\
\hline Admission & $250(9.1)$ & $27(3.4)$ & $88(9.7)$ & 118 (12.4) & $17(22.1)$ \\
\hline \multicolumn{6}{|l|}{ Wound characteristics } \\
\hline Cerebral concussion & $55(2.0)$ & $23(2.9)$ & $9(1.0)$ & $21(2.2)$ & $2(2.6)$ \\
\hline Dislocation & $132(4.8)$ & $50(6.2)$ & $53(5.8)$ & $24(2.5)$ & $5(6.5)$ \\
\hline Fracture & $942(34.3)$ & $219(27.3)$ & $333(36.5)$ & $357(37.4)$ & $33(42.9)$ \\
\hline Open wound & $383(14.0)$ & $116(14.5)$ & $119(13.1)$ & $135(14.1)$ & $13(16.9)$ \\
\hline Sprain & $540(19.7)$ & $133(16.6)$ & $172(18.9)$ & $225(23.6)$ & $10(13.0)$ \\
\hline Superficial injury & $645(23.5)$ & $241(30.1)$ & $214(23.5)$ & $179(18.7)$ & $11(14.3)$ \\
\hline Others & $48(1.8)$ & $19(2.4)$ & $12(1.3)$ & $14(1.5)$ & $3(3.9)$ \\
\hline \multicolumn{6}{|l|}{ Mechanism } \\
\hline \multicolumn{6}{|l|}{ Operation } \\
\hline Yes & $171(6.2)$ & $21(2.6)$ & $56(6.1)$ & $81(8.5)$ & $13(16.9)$ \\
\hline No & $1,816(66.2)$ & $579(72.3)$ & 600 (65.8) & 598 (62.6) & 39 (50.7) \\
\hline Unknown & $758(27.6)$ & $201(25.1)$ & $256(28.1)$ & 276 (28.9) & 25 (32.5) \\
\hline
\end{tabular}

Values are presented as median (interquartile range) or number (\%).

ED, emergency department.

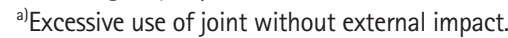

has increased over time, and trampoline-containing facilities continue to grow in number, there is no appropriate official injury prevention policy from some authoritative groups. ${ }^{8}$ This might contribute to the increasing trend of trampoline-related injuries.

The largest number of patients were under the age of 12 years, and the most frequently injured area was a lower extremity. The risk factors for significant injuries requiring admission were age 13 to 18 years, upper extremity injury, fracture, fall, and collision. In Korea, the proportion of pediatric trampoline-related injuries relative to the total number of injured patients is increasing an- nually. Previous studies in the United States, Australia, and elsewhere have shown similar results. ${ }^{1,13}$ Thus, pediatric trampolinerelated injury is still an emerging concern. In this study, trampoline-related injuries had a hospitalization rate of 9.2\%. This rate is similar to the admission rate reported for the US, both in general (9.9\%) and for trampoline park injuries in particular (8.8\%), and lower than that reported in a study in New South Wales, Australia (12.5\%)., ${ }^{4,1314} \mathrm{~A}$ previous study conducted in Australia found that children aged 5 to 9 years comprised $46.2 \%$ of admitted patients with a trampoline-related injury. Patients aged 15 to 19 
Table 2. Characteristics of trampoline-related injury by ED disposition

\begin{tabular}{|c|c|c|}
\hline \multirow{2}{*}{ Characteristics } & \multicolumn{2}{|c|}{ ED disposition } \\
\hline & Discharge $(n=2,482)$ & Admission $^{a)}(n=263)$ \\
\hline Age (yr) & $5(3-8)$ & $7(5-10)$ \\
\hline \multicolumn{3}{|l|}{ Age group (yr) } \\
\hline Toddler (0-3) & $771(31.1)$ & 30 (11.4) \\
\hline Preschooler (4-6) & $818(33.0)$ & $94(35.7)$ \\
\hline Schooler (7-12) & 835 (33.6) & $120(45.6)$ \\
\hline Teenager (13-18) & $58(2.3)$ & $19(7.2)$ \\
\hline Sex, male & $1,350(54.4)$ & $140(53.2)$ \\
\hline \multicolumn{3}{|l|}{ Anatomical site } \\
\hline Head and neck & 692 (27.9) & $18(6.8)$ \\
\hline Trunk & $69(2.8)$ & $5(1.9)$ \\
\hline Upper extremity & $492(19.8)$ & $175(66.5)$ \\
\hline Lower extermity & $1,162(46.8)$ & $65(24.7)$ \\
\hline Unspecified & $67(2.7)$ & $0(0)$ \\
\hline \multicolumn{3}{|l|}{ Injury place } \\
\hline Indoor & $1,739(70.1)$ & $169(64.3)$ \\
\hline Outdoor & $674(27.2)$ & $87(33.1)$ \\
\hline Unspecified & $69(2.8)$ & $7(2.7)$ \\
\hline \multicolumn{3}{|l|}{ Wound characteristics } \\
\hline Cerebral concussion & $54(2.2)$ & $1(0.4)$ \\
\hline Dislocation & $127(5.1)$ & $5(1.9)$ \\
\hline Fracture & $700(28.2)$ & $242(92.0)$ \\
\hline Open wound & $379(15.3)$ & $4(1.5)$ \\
\hline Sprain & $534(21.5)$ & $6(2.3)$ \\
\hline Superficial injury & $642(25.9)$ & $3(1.1)$ \\
\hline Others & $46(1.9)$ & $2(0.8)$ \\
\hline \multicolumn{3}{|l|}{ Mechanism } \\
\hline Collision & $420(16.9)$ & $43(16.4)$ \\
\hline Excessive use & $686(27.6)$ & 34 (12.9) \\
\hline Fall down & $300(12.1)$ & $61(23.2)$ \\
\hline Contact with human & $349(14.1)$ & $30(11.4)$ \\
\hline Slip & $650(26.2)$ & 91 (34.6) \\
\hline Others & $77(3.1)$ & $4(1.5)$ \\
\hline Operation & $42(1.7)$ & $129(49.1)$ \\
\hline
\end{tabular}

Values are presented as median (interquartile range) or number (\%). $E D$, emergency department.

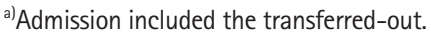

years accounted for 3.3\%. ${ }^{1}$ However, in this study, most of the injured patients were under 12 years of age, but patients between 13 and 18 years of age had the highest odds ratio for admission. These results indicate that older children have fewer trampolineassociated ED visits and a higher risk of hospitalization. Previous studies have shown that trampoline-related injuries are more likely to result from dangerous movements, such as somersaults., ${ }^{3,15}$ In this study, the higher odds ratio values in patients between the ages of 13 and 18 years may occur because children in this group tend to engage in dangerous behaviors that can cause damage requiring hospitalization.

Several previous studies identified the upper extremity as the most common injury site. ${ }^{1,16-20}$ Unlike previous studies, our study found that lower extremity injuries were the most common, but the odds ratio for hospitalization was higher for patients with upper extremity injuries.

Previous studies of trampoline-induced orthopedic injury have shown that fractures occur frequently in the upper extremities. ${ }^{4}$ It is known that lower extremities are subject to many minor injuries, such as soft tissue injury and strain. ${ }^{15,19-22}$ In Korea, National Health Insurance provides universal coverage for the entire Korean population, so the threshold for ED use is relatively low. In addition, it is usually not easy to care for injured pediatric patients at primary clinics outside the ED in Korea. Because pediatricians in local clinics may have a lack of training and limited experience in handling such injuries, they may feel unprepared to treat these patients. These factors may have contributed in part to our results.

In other studies, falling from the trampoline accounted for 27\% to $39 \%$ of all trampoline-associated injuries. ${ }^{18,21,23}$ In our study, slips and LS: excessive use were the two most common mechanisms of injury (accounting for $27.0 \%$ and $26.2 \%$ of cases, respectively); in contrast, falls accounted for only $13.2 \%$. However, multivariable logistic regression results showed that falls and collisions were the most dangerous mechanisms of injury. Additionally, the study's findings may reflect Korean people's tendency to visit the ED even for minor injuries.

This study has US: several limitations. First, in this study, we looked for factors affecting admission instead of assessing injury severity itself. There are several scoring systems for injury severity in pediatric patients, such as the injury severity score, revised trauma score, and pediatric trauma score, but which is best is controversial. ${ }^{24-26}$ Injury severity score is calculated using the diagnosis name, but this may not be entered correctly. There is also controversy as to what score corresponds to serious damage. In the case of the revised trauma score, blood pressure and respiratory rate, which are used as variables, change with age, and are of limited use in children. In the case of the pediatric trauma score, we could not calculate scores because patient weight is not recorded in the EDISS. Hospitalization is limited in representing the severity of injury because it can be greatly affected by differences among hospitals. In hospitals that have room to spare, patients may be hospitalized for relatively minor injuries that require shortterm follow-up, or because the parents request hospitalization. However, the EDIIS registry can be assumed to include hospitals with similar levels and environments, and data are collected from specialized hospitals as well as general hospitals. The result of hospitalization has no missing value, and its reliability is guaranteed. Thus, we choose the result of hospitalization as our outcome. 
Table 3. OR for the risk factors associated hospital admission in trampoline-related injuries

\begin{tabular}{|c|c|c|c|c|}
\hline \multirow{2}{*}{ Characteristics } & \multicolumn{2}{|c|}{ Unadjusted } & \multicolumn{2}{|c|}{ Adjusted $^{\text {a) }}$} \\
\hline & $\mathrm{OR}$ & $95 \% \mathrm{Cl}$ & OR & $95 \% \mathrm{Cl}$ \\
\hline \multicolumn{5}{|l|}{ Age group (yr) } \\
\hline Toddler (0-3) & 0.27 & $0.18-0.41$ & 0.38 & $0.24-0.61$ \\
\hline Preschooler (4-6) & 0.80 & $0.60-1.07$ & 0.75 & $0.54-1.05$ \\
\hline Schooler (7-12) & Reference & & Reference & \\
\hline Teenager (13-18) & 2.28 & $1.31-3.96$ & 3.53 & $1.73-7.17$ \\
\hline \multicolumn{5}{|l|}{ Anatomical site } \\
\hline Head and neck & 0.47 & $0.27-0.79$ & 0.98 & $0.49-1.99$ \\
\hline Trunk & 1.26 & $0.49-3.20$ & 2.61 & $0.83-8.19$ \\
\hline Upper extremity & 6.33 & $4.67-8.57$ & 2.62 & $1.82-3.77$ \\
\hline Lower extremity & Reference & & Reference & \\
\hline Unspecified & 1.00 & & 1.00 & \\
\hline \multicolumn{5}{|l|}{ Injury place } \\
\hline Indoor & Reference & & Reference & \\
\hline Outdoor & 1.33 & $1.01-1.75$ & 1.11 & $0.81-1.53$ \\
\hline Unknown & 1.04 & $0.47-2.31$ & 1.03 & $0.41-2.58$ \\
\hline \multicolumn{5}{|l|}{ Wound characteristics } \\
\hline Sprain & Reference & & Reference & \\
\hline Cerebral concussion & 1.65 & $0.19-13.94$ & 1.31 & $0.14-12.21$ \\
\hline Dislocation & 3.50 & $1.05-11.66$ & 2.17 & $0.62-7.52$ \\
\hline Fracture & 30.77 & $13.58-69.71$ & 18.48 & $7.95-42.95$ \\
\hline Open wound & 0.94 & $0.26-3.35$ & 0.74 & $0.19-2.96$ \\
\hline Superficial injury & 0.42 & $0.10-1.67$ & 0.29 & $0.07-1.20$ \\
\hline Others & 3.87 & $0.76-19.72$ & 2.97 & $0.54-16.22$ \\
\hline \multicolumn{5}{|l|}{ Injury mechanism } \\
\hline Excessive use & Reference & & Reference & \\
\hline Slip & 2.82 & $1.88-4.25$ & 1.62 & $1.00-2.63$ \\
\hline Fall & 4.10 & $2.64-6.38$ & 2.28 & $1.35-3.86$ \\
\hline Collision & 2.07 & $1.30-3.29$ & 2.04 & $1.15-3.60$ \\
\hline Contact with human & 1.73 & $1.04-2.88$ & 1.32 & $0.74-2.37$ \\
\hline Others & 1.05 & $0.36-3.03$ & 2.56 & $0.72-9.12$ \\
\hline
\end{tabular}

$\mathrm{OR}$, odds ratio; $\mathrm{Cl}$, confidence interval.

${ }^{\text {a) }}$ Adjusted by age group, anatomical site, injury place, wound characteristics, and injury mechanism.

Second, there was a change in the number of hospitals that participated in the survey during the study. The hospitals that participated in the EDIIS registry were selected by the Korea Centers for Disease Control and Prevention in light of their geographic location and number of patients. However, there is a possibility that the differences in the number of participating hospitals may have affected the results, especially if hospitals that treat many childhood patients were added during the course of our study.

Third, although EDIIS is a national injury database, not all EDs in Korea were included in the EDIIS. Therefore, the results of this study may not be fully representative. Further research and use of a more representative database are needed.

In summary, trampoline-related injuries in children are increasing in Korea. Most occur in children under the age of 12 years, but children between the ages of 13 and 18 years are at a greater risk for hospitalization. Although damage to the lower extremities is common, damage to an upper extremity increases the likelihood of hospitalization. Based on this study, general guidelines and policies for the prevention of injury are necessary and should they focus mainly on the protection of the upper and lower extremities and on the prevention of collisions and falls.

\section{CONFLICT OF INTEREST}

No potential conflict of interest relevant to this article was reported. 


\section{REFERENCES}

1. Ashby K, Pointer S, Eager D, Day L. Australian trampoline injury patterns and trends. Aust N Z J Public Health 2015;39:491-4.

2. Eberl R, Schalamon J, Singer G, Huber SS, Spitzer P, Hollwarth ME. Trampoline-related injuries in childhood. Eur J Pediatr 2009;168:1171-4.

3. Hammer A, Schwartzbach AL, Paulev PE. Some risk factors in trampolining illustrated by six serious injuries. Br J Sports Med 1982;16:27-32.

4. Loder RT, Schultz W, Sabatino M. Fractures from trampolines: results from a national database, 2002 to 2011. J Pediatr Orthop 2014;34:683-90.

5. Korhonen L, Salokorpi N, Suo-Palosaari M, Pesala J, Serlo W, Sinikumpu JJ. Severe trampoline injuries: incidence and risk factors in children and adolescents. Eur J Pediatr Surg 2018; 28:529-33.

6. Sharwood LN, Adams S, Blaszkow T, Eager D. Increasing injuries as trampoline parks expand within Australia: a call for mandatory standards. Aust N Z J Public Health 2018;42:153-6.

7. Council on Sports Medicine and Fitness, American Academy of Pediatrics, Briskin S, LaBotz M. Trampoline safety in childhood and adolescence. Pediatrics 2012;130:774-9.

8. Korea Consumer Agency. Report of trampoline facility safety survey [Internet]. Eumseong: Korea Consumer Agency; 2013 [cited 2018 Dec 20]. Available from: https://www.kca.go.kr/ home $/ /$ board/download.do?menukey $=4062 \&$ fno $=10008142$ \&tbid $=00000146 \mathrm{Ctdid}=1001387878$.

9. Shin YW, Hong CW, Lee OJ, Park SY. The incidence of pediatric trampoline injury: statistics from a single institution. J Korean Orthop Assoc 2018;53:129-35.

10. Choi ES, Shin YW. Trampoline-related injuries in Korea. J Korean Med Assoc 2018;61:111-5.

11. Choi ES, Jang JH, Woo JH, Choi JU, Cho JS, Yang HJ. Pediatric trampoline-related injuries in a nationwide registry in South Korea, 2011 to 2016. Yonsei Med J 2018;59:989-94.

12. Park GJ, Ro YS, Shin SD, Song KJ, Hong KJ, Jeong J. Preventive effects of car safety seat use on clinical outcomes in infants and young children with road traffic injuries: a 7-year observational study. Injury 2018;49:1097-103.

13. Kasmire KE, Rogers SC, Sturm JJ. Trampoline park and home trampoline injuries. Pediatrics 2016;138:e20161236.

14. Mulligan CS, Adams $S$, Brown J. Paediatric injury from indoor trampoline centres. Inj Prev 2017;23:352-4.

15. Paker N. Trampoline injuries in the world and in Turkey. Turk J Phys Med Rehabil 2017;63:275-80.

16. Sandler G, Nguyen L, Lam L, Manglick MP, Soundappan SS, Holland AJ. Trampoline trauma in children: is it preventable? Pediatr Emerg Care 2011;27:1052-6.

17. Chalmers DJ, Hume PA, Wilson BD. Trampolines in New Zealand: a decade of injuries. Br J Sports Med 1994;28:234-8.

18. McDermott C, Quinlan JF, Kelly IP. Trampoline injuries in children. J Bone Joint Surg Br 2006;88:796-8.

19. Linakis JG, Mello MJ, Machan J, Amanullah S, Palmisciano LM. Emergency department visits for pediatric trampoline-related injuries: an update. Acad Emerg Med 2007;14:539-44.

20. Smith GA, Shields BJ. Trampoline-related injuries to children. Arch Pediatr Adolesc Med 1998;152:694-9.

21. Shankar A, Williams K, Ryan M. Trampoline-related injury in children. Pediatr Emerg Care 2006;22:644-6.

22. Hauth $E_{\text {, Jaeger }} H_{1}$ Luckey $P$, Beer $M$. MR imaging for detection of trampoline injuries in children. BMC Pediatr 2017;17:27.

23. Alexander K, Eager D, Scarrott C, Sushinsky G. Effectiveness of pads and enclosures as safety interventions on consumer trampolines. Inj Prev 2010;16:185-9.

24. Beattie TF, Currie CE, Williams JM, Wright P. Measures of injury severity in childhood: a critical overview. Inj Prev 1998;4: 228-31.

25. Narci A, Solak O, Turhan-Haktanir N, et al. The prognostic importance of trauma scoring systems in pediatric patients. Pediatr Surg Int 2009;25:25-30.

26. Lee HK, Do BS, Lee SB. Appropriateness of the use of emergency medical services and propensities toward choice by local residents of hospitals. J Korean Soc Emerg Med 2010;21: 525-30. 